\title{
The Use of a Flexible Calix[4] arene Template to Stabilize a Cyclooctatetraindiyl Samarium-Potassium Complex
}

\author{
Geoffroy Guillemot, ${ }^{1,2}$ Euro Solari, ${ }^{1}$ Carlo Floriani, ${ }^{1}$ and Thierry Prangé ${ }^{3}$ \\ ${ }^{1}$ Institut de Chimie Moléculaire et Biologique, Ecole Polytechnique Fédérale de Lausanne, EPFL-BCH, CH-1015 Lausanne, Switzerland \\ ${ }^{2}$ Institut Parisien de Chimie Moléculaire (UMR 7201-CNRS), Université Pierre et Marie Curie, Case Courrier 42, 4 Place Jussieu, \\ 75252 Paris Cedex 05, France \\ ${ }^{3}$ Laboratoire de Cristallographie et RMN Biologiques (UMR 8015-CNRS), Faculté de Pharmacie, Université Paris Descartes, \\ 4 Avenue de l'Observatoire, 75006 Paris, France \\ Correspondence should be addressed to Prangé Thierry; thierry.prange@parisdescartes.fr
}

Received 13 May 2013; Accepted 3 October 2013

Academic Editors: M. Akkurt, J. Jasinski, and L. MacGillivray

Copyright (C) 2013 Guillemot Geoffroy et al. This is an open access article distributed under the Creative Commons Attribution License, which permits unrestricted use, distribution, and reproduction in any medium, provided the original work is properly cited.

\begin{abstract}
A sandwich compound of cyclooctatetraendiyl $(\mathrm{COT})^{2-}$ samarium-potassium was synthesized and analyzed using a flexible calix [4] arene dianion. This compound, $\left[p\right.$-tBu-calix $\left.[4]-(\mathrm{OMe})_{2}(\mathrm{O})_{2}\right]$ arenediyl-samarium- $(\eta 8$-cyclooctatetraendiyl)-potassium $\mu$ (tetrahydrofurane $)_{3}$, is constructed as a linear sequence $\mathrm{L}-\mathrm{Sm}-\mathrm{L}^{\prime}-\mathrm{K}-\mathrm{L}^{\prime \prime}$, where $\mathrm{L}, \mathrm{L}^{\prime}$, and $\mathrm{L}^{\prime \prime}$ are specific ligands with $\mathrm{L}=\mathrm{O}, \mathrm{O}$ dimethyl-calix[4]arene ${ }^{2-}, \mathrm{L}^{\prime}=$ cyclo-octatetraendiyl, and $\mathrm{L}^{\prime \prime}=$ tetrahydrofurane templates.
\end{abstract}

\section{Introduction}

For a long time, the organometallic chemistry of lanthanides (Ln) [1] has been dominated by the use of polycyclic hydrocarbons including the cyclopentadienyl anion or the cyclooctatetraendiyl dianion, as exemplified by the well-known lanthanocene $\left[\mathrm{Cp}_{2} \operatorname{Ln}(\mathrm{III})\right]^{+}[2]$ and [bis(cyclooctatetraenyl)Ln] $]^{-}$complexes [3]. In the last two decades, the organometallic and redox chemistry of these hard metal ions has been extensively developed by the introduction of amido, thiolato, and aryloxo ligands as well as macrocyclic ligands, such as octa-alkyl-porphyrinogens and calix [4]arenes $[4,5]$, and a number of such examples of $\mathrm{COT}^{2-}$ complexes have recently been published [6-10]. Calixarenes are useful building blocks in supramolecular chemistry for complexing metallic cations [11]; the use of calix[4] arene anions [12] brings significant peculiarities: (i) the electron-rich environment provided by the oxygen donor atoms forms an ideal platform for developing the organometallic and redox chemistry of lanthanides, (ii) the quasi-planar arrangement of the four oxygen atoms resulting from the cone conformation of the calix allows the formation of "half-sandwich"-type metallic complexes, and (iii) it can accommodate up to 12 electrons to the metal centre depending on the degree of $\pi$-donation. Therefore, it came out that an interesting analogy can be drawn between the quasi-planar calix[4]arene polyanion and its electronically similar cyclooctatetraendiyl dianion [13] in the attempt to develop new scaffoldings in organometallic chemistry of Lanthanides. In the present study we report on the synthesis and crystallographic analysis of the mixed cyclooctatetraendiyl samarium-potassium complex: [p-tBu-calix [4]-(OMe $\left.)_{2}(\mathrm{O})_{2}\right]$ arenediyl samarium-( $\eta 8$-cyclooctatetraendiyl) potassium $-\mu(\mathrm{THF})_{3}$, stabilized by a flexible calix[4]arene dianion template, a compound that widens the ability of unsymmetrical calix[4]arene as a useful and adaptable ligand in organometallic chemistry.

\section{Experimental}

A solution of cyclooctatetraendiide dipotassium in THF [14] $(8.8 \mathrm{~mL}, 0.275 \mathrm{M}, 2.42 \mathrm{mmol})$ was added dropwise to a suspension of $2(4.6 \mathrm{~g}, 2.47 \mathrm{mmol})$ [15] in THF $(150 \mathrm{~mL})$ 
at $-30^{\circ} \mathrm{C}$. The reaction mixture was stirred overnight while slowly warming to room temperature, leading to a suspension of a white solid in a red solution. The solid was filtered off, the solution was concentrated to $c a .30 \mathrm{~mL}$, and subsequently kept at $3^{\circ} \mathrm{C}$. The orange precipitate was collected and dried in vacuo. Yield: $2.1 \mathrm{~g}(34 \%)$ of 3.

Elemental analysis calcd (\%) for $\mathrm{C}_{70} \mathrm{H}_{98} \mathrm{KO}_{8} \mathrm{Sm}$ (1257.04): C 66.88, H 7.86; found: C 66.49, H 7.60. Crystals suitable for Xray crystallography were grown at $3^{\circ} \mathrm{C}$ from a THF solution. Crystal data: Triclinic, with parameters $a=14.4610$ (2) $\AA$; $b=15.4330(4) \AA ; c=6.5550(4) \AA ; \alpha=106.02(5)^{\circ} ; \beta=$ 98.62(5) $)^{\circ} \gamma=102.08(5)^{\circ}$, and $V=3387(1) \AA^{3}$. Crystals were very sensitive to air and moisture. They were fished out under neutral atmosphere or under oil using a nylon loop and immediately cryocooled in liquid nitrogen.

Diffraction data were collected at $T=143 \mathrm{~K}$ on a Mar345 Image Plate detector $\left(3^{\circ}<2 \theta<52^{\circ}\right)$ using the Mo K $\alpha$ wavelength in the rotation method (180 steps of one degree per frame). Diffraction data were processed with the HKL package [16] (22696 recorded reflections; redundancy $\sim 2$; $R_{\text {symm }}=0.028$; completeness $\left.92 \%\right)$. No absorption correction was applied. The final data set was reformatted for structure determination and refinement using the SHELXS/L programs [17].

The structure was solved in centrosymmetric $P-1$ space group by direct methods. During refinements, a solvated THF molecule was located highly disordered in the packing with high temperature factors. Hydrogen atoms were kept at their theoretical places and refined as riding atoms to their bonded carbon. The four terbutyls of the calix[4] arene ligand known to still rotate at low temperature were refined as restrained groups. The final $R$ was 0.0514 (10196 observed data with $I>2 \sigma(I))$ and $w R 2=0.1335$ (calculated with the 11873 unique squared reflections having $I>0$ ). The coordinates were deposited with the CCDC, 12 Union Road, Cambridge CB2 1EZ, UK, ref. 880827.

\section{Discussion}

The starting materials we devised in our previous work on lanthanides chemistry are displayed in Scheme 1. The use of the bis-O-methylated calix[4]arene allows tuning of the macrocyclic charge [12] to a value appropriate for entering the chemistry of lanthanides. The reaction of $\mathrm{LnCl}_{3}(\mathrm{THF})_{2}$ with the lithium or sodium salt of $\left[p\right.$-tBu-calix $\left.[4]-(\mathrm{OMe})_{2}(\mathrm{OH})_{2}\right]$ [18] led to the formation of dimeric complexes $2\left[p \text {-tBu-calix }[4]-(\mathrm{OMe})_{2}(\mathrm{O})_{2}-\mathrm{Ln}(\mathrm{THF})\right]_{2}(\mu-\mathrm{Cl})_{2}$ in which the metal ions are bridged by two chloride anions. Under dinitrogen, the reduction of these lanthanide complexes $(\mathrm{Ln}=\mathrm{Pr}, \mathrm{Sm})$ by sodium naphthalenide has been reported to carry out the four-electron reduction of dinitrogen to a $\left(\mu_{3}-\eta^{2}: \eta^{2}: \eta^{2}-\mathrm{N}_{2}\right)$ moiety supported by a trinuclear complex and exhibiting a very high degree of $d(\mathrm{~N}-\mathrm{N})$ bond elongation [15]. The analogy between $\mathrm{C}_{8} \mathrm{H}_{8}{ }^{2-}$ and $\left[p \text {-tBu-calix }[4]-(\mathrm{OMe})_{2}(\mathrm{O})_{2}\right]^{2-}$ dianions led us to investigate the exchange reaction between $\left.\quad[p \text {-tBu-calix[4]-(OMe })_{2}(\mathrm{O})_{2} \mathrm{Sm}(\mathrm{THF})\right]_{2}(\mu \text {-Cl })_{2}$ and $\mathrm{C}_{8} \mathrm{H}_{8} \mathrm{~K}_{2}$. This gave the mixed sandwich compound 3 .
TABLE 1: Calix[4]arene elliptical parameters ${ }^{\mathrm{a}}$ in 3 compared to compounds 2 and $4^{\mathrm{a}}$.

\begin{tabular}{|c|c|c|c|c|}
\hline Compound & $\mathrm{Da}(\AA)$ & $\mathrm{Db}(\AA)$ & $\varepsilon$ & Reference \\
\hline \multicolumn{5}{|l|}{3} \\
\hline Ring I & $9.937(5)$ & $5.467(5)$ & 0.835 & - \\
\hline Ring II & $9.854(5)$ & $5.396(5)$ & 0.836 & - \\
\hline \multicolumn{5}{|l|}{2} \\
\hline Ring I & $9.689(3)$ & $5.816(3)$ & 0.799 & [15] \\
\hline \multicolumn{5}{|l|}{4} \\
\hline Ring I & $8.861(4)$ & $7.752(4)$ & 0.484 & id \\
\hline Ring II & $9.668(4)$ & $7.441(4)$ & 0.638 & id \\
\hline Ring III & $9.503(4)$ & $5.694(4)$ & 0.800 & id \\
\hline
\end{tabular}

${ }^{\mathrm{a}} \mathrm{Da}, \mathrm{Db}$, and $\varepsilon$ are the long and short distances and eccentricity of the ellipse which encompasses the four para aromatic carbons of the ligand.

The content of the asymmetric unit is shown in Figure 1. The samarium-potassium complex adopts a linear structure with a cylindrical shape of $15 \AA$ in length and forms a sandwich scaffold with the samarium and potassium cations interspersed with the three different ligands, the calix[4] arene dianion on one side of the samarium (ligand L), the cyclooctatetraendiyl dianion (ligand $\mathrm{L}^{\prime}$ ) in between samarium and potassium, and three coordinating tetrahydrofuranes (THF) on the other side of the potassium (ligand $\mathrm{L}^{\prime \prime}$ ).

Ligand L. On one side, a dissymmetric calix[4] arene is used with alternate protected (methoxy) and free (oxygen anion) polar atoms. It interacts with the samarium cation at short distance with only two oxygens, forcing the skeleton to assume a very constrained elliptical conformation with the Sml-O(2) and Sml-O(4) distances, particularly long $\left(d_{2}=\right.$ 2.694(3) $\AA$ and $\left.d_{4}=2.795(4) \AA\right)$ compared to the two others, Sm1-O(1) and Sm1-O(3) $\left(d_{1}=2.189(3) \AA\right.$ and $d_{3}=$ $2.186(3) \AA$ ). Table 1 reports the macrocycle ring eccentricity compared with two other nonsymmetric calix[4] arene compounds, the parent dimer $(\mathrm{L}-\mathrm{SmCl})_{2} 2$, and the corresponding $\left(\mathrm{L}_{3} \mathrm{Sm}_{2} \mathrm{~N}_{2}\right)$ complex 4 (Scheme 1), all using the same flexible ligand. The calix[4] ligand in the asymmetric unit of 3 has a much higher $\varepsilon$ value than those observed in the structures of $\mathbf{2}$ and $\mathbf{4}$ [15]. It is interesting to note that, in the dinitrogen complex 4 , the three calix[4] arene ligands adapt themselves to the central $\mathrm{Sm}_{2}-\mathrm{N}_{2}$ cluster, through their high plasticity. This is evidenced by the different values of each $\varepsilon$ parameter (Table 1).

$L^{\prime}$-The Central Ligand. The cyclooctatetraindiyl dianion adopts a perfect planar configuration due to its aromaticity and supports a full coordination with both the potassium and samarium cations located on opposite sides. Within the dianion, the average bond distance is $\langle d\rangle=1.413 \AA$ with s.d. $\sim 0.03 \AA$, while the mean angle is around the ideal value of $3 \pi / 4$ with s.d. $\sim 1.0^{\circ}$. These values correspond to a nearly perfect, unconstrained octagon. The two samarium and potassium cations at $4.552(2) \AA$ from each other are perpendicular to the center of the ring with individual distances $=2.09$ and $2.46 \AA$ from the COT plane, respectively. These distances are relevant to a similar partition of charges 


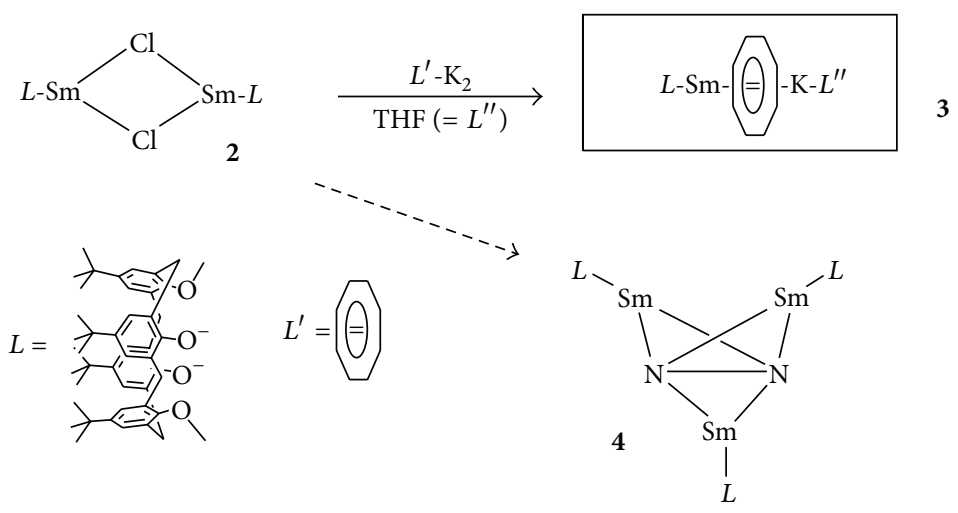

Scheme 1: Preparation of the samarium-potassium complex 3 from calix[4]arene $(\mathrm{OMe})_{2}(\mathrm{OH})_{2}$ samarium chloride 2.

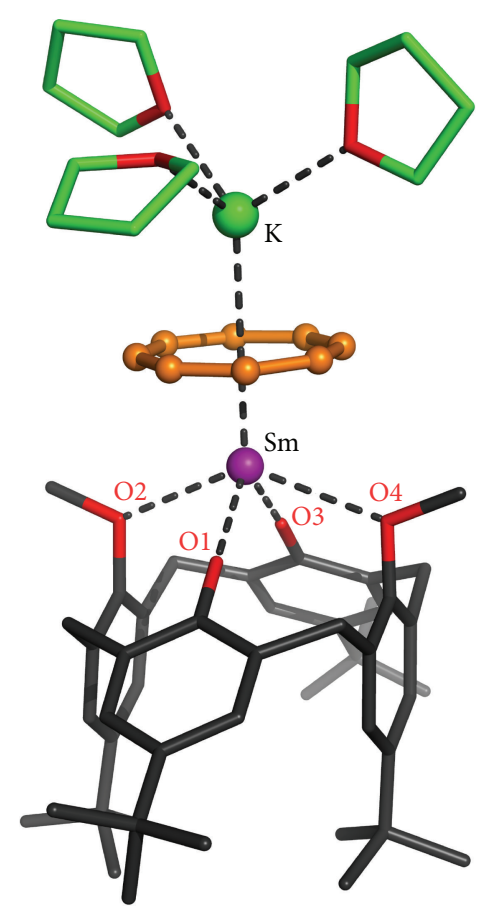

FIGURE 1: Overall view of the samarium-potassium sandwich structure of 3. The solvated THF molecule and hydrogens are omitted for clarity. The three ligands are given in different colors: $\mathrm{L}$ is in black, COT is in orange, and the potassium THFs (ligand $\mathrm{L}^{\prime \prime}$ ) are in green.

on both sides according to the respective ionic radii of $\mathrm{Sm}^{3+}$ and $\mathrm{K}^{+}(\sim 1.1$ and $1.33 \AA)$.

$L^{\prime \prime}$-Potassium Template. The potassium ion completes on the other side its coordination sphere with three molecules of THF.

Solvation. In addition to the title molecule in the asymmetric unit, there is an additional solvated THF molecule (not shown in Figure 1) with very large thermal parameters. This molecule lies in the vicinity of the $\mathrm{L}^{\prime \prime}$ ligand.

\section{Conclusion}

The present structure of a mixed rare earth-potassium complex of cyclooctatetraindiyl dianion, together with the two other crystal structures of $\mathbf{2}$ and $\mathbf{4}$, illustrates and generalizes how the plasticity of a calix[4] arene dianion with alternate $\mathrm{MeO} / \mathrm{O}$-polar groups can be used in the building of stable scaffolds in reactive organometallic systems of lanthanides.

\section{References}

[1] W. J. Evans, "The importance of questioning scientific assumptions: some lessons from f element chemistry," Inorganic Chemistry, vol. 46, no. 9, pp. 3435-3449, 2007.

[2] C.-T. Qian and C.-J. Zhu, "Synthesis, structure and reactivity of lanthanocene complexes," Chinese Journal of Chemistry, vol. 20, no. 6 , pp. 519-535, 2002.

[3] U. Kilimann and F. T. Edelmann, "Neue cyclooctatetraenyllanthanid(III)-komplexe," Journal of Organometallic Chemistry, vol. 444, no. 1-2, pp. C15-C17, 1993.

[4] M. F. Lappert, W. J. Evans, and D. M. P. Mingos, "Recent advances in the organometallic chemistry of the group 3 and lanthanoid elements," Journal of Organometallic Chemistry, vol. 647 , no. $1-2,2002$

[5] F. T. Edelmann, "Lanthanides and actinides: annual survey of their organometallic chemistry covering the year 2008," Coordination Chemistry Reviews, vol. 255, no. 15-16, pp. 18341920, 2011.

[6] J. Xia, Z. Jin, and W. Chen, "Synthesis and crystal structure of a new lanthanide cyclooctatetraene complex $\left(\eta^{8}-\mathrm{C}_{8} \mathrm{H}_{8}\right) \operatorname{Er}\left(\mu-\eta^{8}\right.$ $\left.\mathrm{C}_{8} \mathrm{H}_{8}\right) \mathrm{K}\left(\mu-\eta^{8}-\mathrm{C}_{8} \mathrm{H}_{8}\right) \operatorname{Er}\left(\mu-\eta^{8}-\mathrm{C}_{8} \mathrm{H}_{8}\right) \mathrm{K}(\mathrm{THF})_{4}$," Journal of the Chemical Society, Chemical Communications, no. 17, pp. 12141215, 1991.

[7] U. Kilimann, M. Schäfer, R. Herbst-Irmer, and F. T. Edelmann, "Cyclooctatetraenyl-komplexe der frühen übergangsmetalle und lanthanoide. IV. Strukturchemie des anionisichen sandwich-komplexes $\left[\mathrm{Ce}(\mathrm{COT})_{2}\right]^{-}$," Journal of Organometallic Chemistry, vol. 469, no. 1, pp. C15-C18, 1994.

[8] J. Xia, X. Zhuang, Z. Jin, and W. Chen, "Synthesis and crystal structure of $\left[\left(\mathrm{C}_{8} \mathrm{H}_{8}\right)_{3}\left(\mathrm{C}_{6} \mathrm{H}_{5} \mathrm{CH}_{2} \mathrm{C}_{5} \mathrm{H}_{4}\right) \mathrm{Nd}_{2} \mathrm{~K}(\mathrm{THF})_{3}\right]$," Polyhedron, vol. 15, no. 19, pp. 3399-3403, 1996. 
[9] J. Jin, Z. Jin, G. Wei, and W. Chen, “ $\left(\mu 2-\eta^{8}, \eta^{8}\right.$-cyclooctatetraenyl $)-\left(\eta^{8}\right.$-cyclo-octatetraenyl)-tris(tetrahydrofuranO)-samarium-sodium," Chinese Journal of Inorganic Chemistry, vol. 9, p. 326, 1993.

[10] W. J. Evans, J. L. Shreeve, and J. W. Ziller, "Synthesis and structure of inverse cyclooctatetraenyl sandwich complexes of Europium(II): $\left[\left(\mathrm{C}_{5} \mathrm{Me}_{5}\right)(\mathrm{THF})_{2} \mathrm{Eu}\right]_{2}\left(\mu-\mathrm{C}_{8} \mathrm{H}_{8}\right.$ and $\left[(\mathrm{THF})_{3} \mathrm{~K}(\mu-\right.$ $\left.\left.\mathrm{C}_{8} \mathrm{H}_{8}\right)\right]_{2}$ Eu," Polyhedron, vol. 14, no. 20-21, pp. 2945-2951, 1995.

[11] J. L. Atwood, G. W. Orr, R. K. Juneja, S. G. Bott, and F. Hamada, "Supramolecular assemblies based on calixarenes," Pure and Applied Chemistry, vol. 65, pp. 1471-1476, 1993.

[12] C. Floriani and R. Floriani-Moro, Metal Reactivity on Oxo Surfaces Modeled by Calix[4]arenes, Kluwer Academic Publishers, Dordrecht, The Nederlands, 2002.

[13] T. Sommerfeld, "A fresh look at aromatic dianions," Journal of the American Chemical Society, vol. 124, no. 6, pp. 1119-1124, 2002.

[14] T. J. Katz, "The cycloöctatetraenyl dianion," Journal of the American Chemical Society, vol. 82, pp. 3784-3785, 1960.

[15] G. Guillemot, B. Castellano, T. Prangé, E. Solari, and C. Floriani, "Use of calix[4] arenes in the redox chemistry of lanthanides: the reduction of dinitrogen by a calix[4] arene-samarium complex," Inorganic Chemistry, vol. 46, no. 13, pp. 5152-5154, 2007.

[16] Z. Otwinowski and W. Minor, "Processing of X-ray diffraction data collected in oscillation mode," Methods in Enzymology, vol. 276, pp. 307-326, 1997.

[17] G. M. Sheldrick, "A short history of SHELX," Acta Crystallographica A, vol. 64, no. 1, pp. 112-122, 2008.

[18] G. Guillemot, E. Solari, C. Rizzoli, and C. Floriani, "Alkali and alkaline-earth-metalated forms of calix[4]arenes: synthons in the synthesis of transition metal complexes," Chemistry-A European Journal, vol. 8, no. 9, pp. 2072-2080, 2002. 

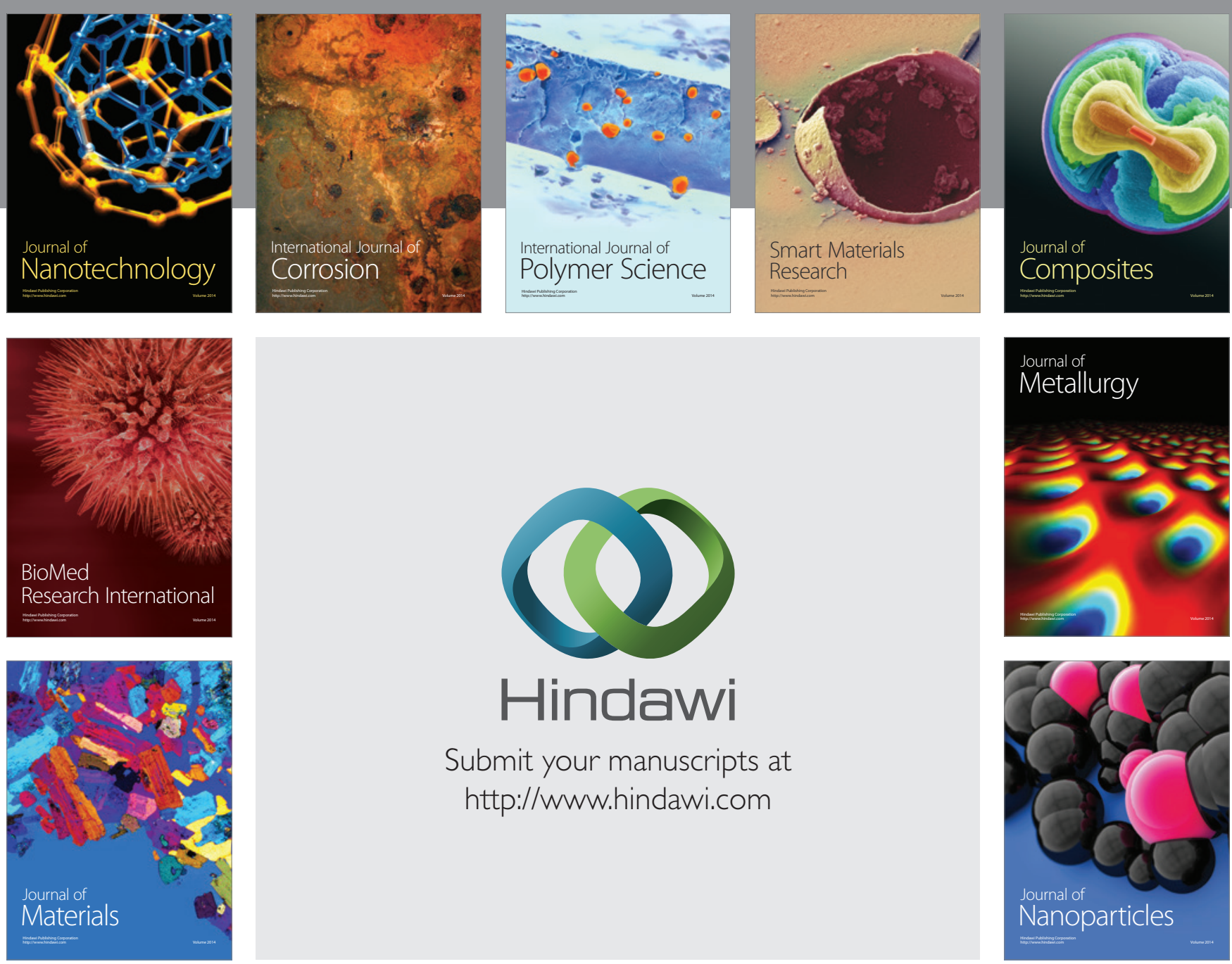

Submit your manuscripts at http://www.hindawi.com
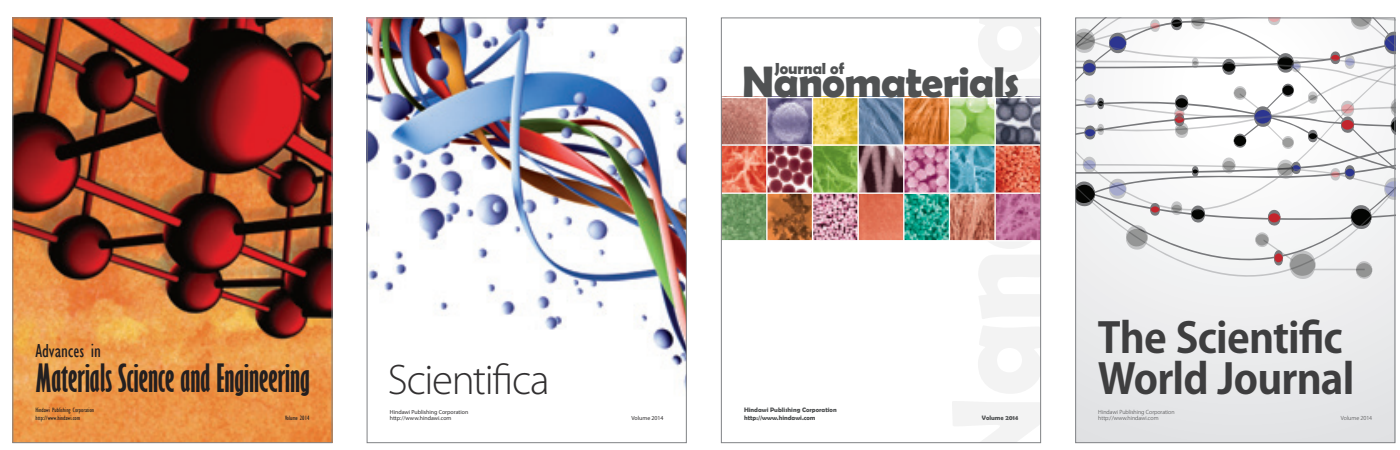

\section{The Scientific World Journal}
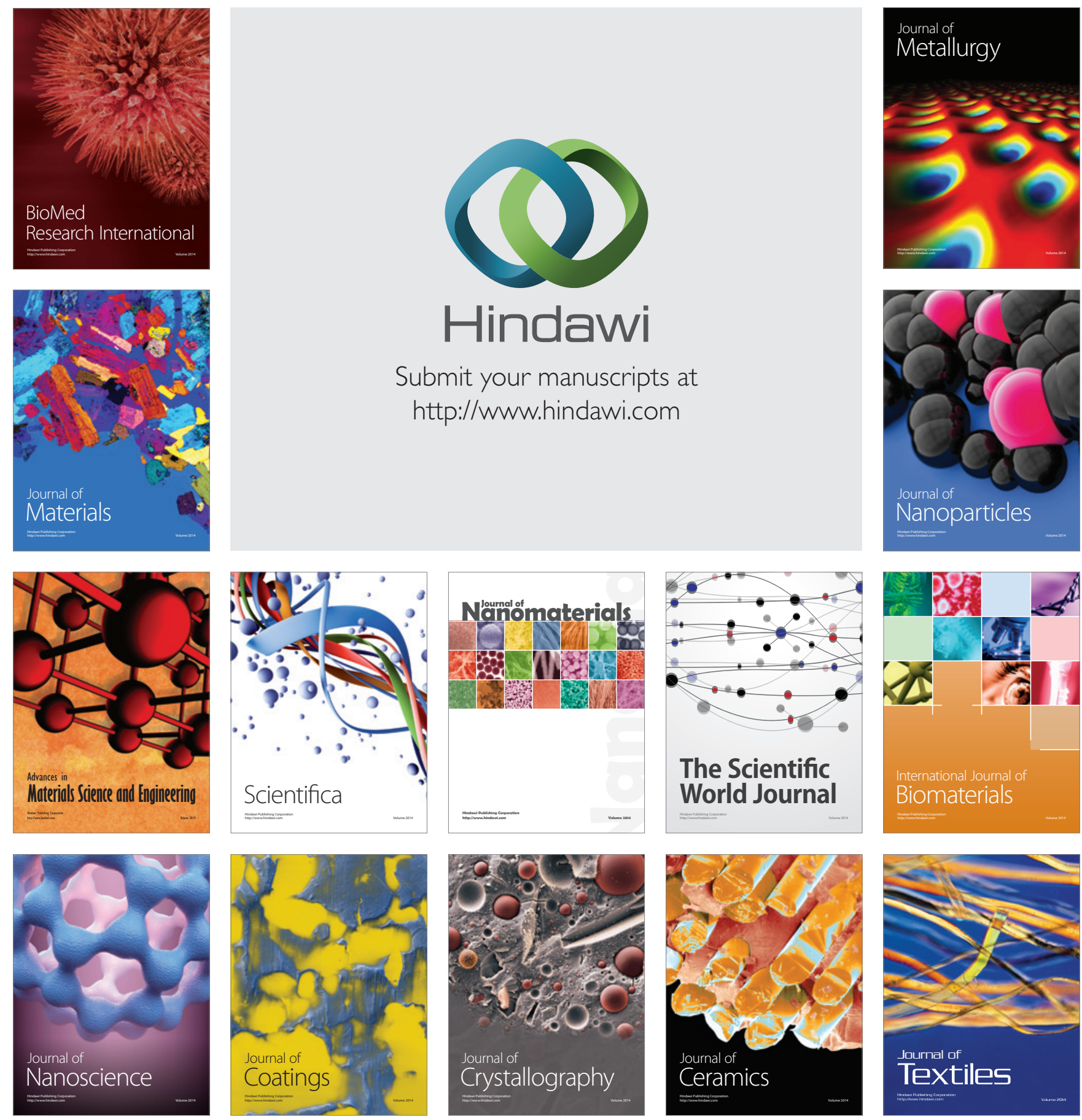